\title{
How Enlightening and Reliable Are Cancer-Related Posts on Social Media Platforms? Opinions of a Sample of Nigerians
}

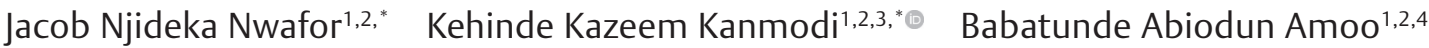

${ }^{1}$ Campaign for Head and Neck Cancer Education (CHANCE)

Programme, Cephas Health Research Initiative Inc, Ibadan, Nigeria

${ }^{2}$ Mental and Oral Health Development Organization Inc, Birnin

Kebbi, Nigeria

${ }^{3}$ Department of Community Health, Aminu Musa Habib College of Health Science and Technology, Yauri, Nigeria

${ }^{4}$ Society for Family Health, Abuja, Nigeria

\author{
Address for correspondence Kehinde Kazeem Kanmodi, \\ BDS, DFM, Campaign for Head and Neck Cancer Education \\ (CHANCE) Programme, Cephas Health Research Initiative Inc, \\ Ibadan 200223, Nigeria \\ (e-mail: kanmodikehinde@yahoo.com).
}

\begin{abstract}
Keywords

- social media

- cancer

- education

- information

- reliability

- Nigeria

Introduction On social media, several pieces of cancer-related information are being shared among people. This study aims to survey the Nigerian public, exploring their opinions on the influence (as per enlightenment) of cancer-related information on social media on them, and explore their opinions on the reliability of cancer-related posts they see on social media platforms.

Methods This study was a descriptive cross-sectional online survey of 236 Nigerians, using an e-questionnaire. Collected data were analyzed using SPSS version 20 software (IBM Corp, New York, NY, United States).

Results The majority (56.4\%) of the respondents were females, $66.5 \%$ were within the age range of 20 to 29 years, and $92.4 \%$ had tertiary level of education. Virtually all (98.7\%) of them had an Internet-enabled phone, and $99.6 \%$ were users of social media. The most used social media platform among them was WhatsApp while the most educative social media platform, according to them, was Facebook. Also, 96.6\% (227/235) of those respondents who were social media users were of the opinion that social media is very useful for cancer education. However, only 68.5\% (161/235) of them had learnt something new about cancer on social media platforms, of which $23.0 \%$ $(37 / 161)$ rated the cancer information they have accessed on social media to be somewhat reliable.

Conclusion Social media is highly influential in educating Nigerians on issues pertaining to cancer. However, not all cancer-related information posted on various social media platforms is reliable; hence, social media users should always take extra caution while consuming cancer-related posts on social media platforms.
\end{abstract}

\footnotetext{
${ }^{*}$ These authors contributed equally.
}

published online May 11, 2021
DOI https://doi.org/

$10.1055 / \mathrm{s}-0041-1729776$

ISSN 2582-4287
(C) 2021. Nitte (Deemed to be University).

This is an open access article published by Thieme under the terms of the Creative Commons Attribution-NonDerivative-NonCommercial-License, permitting copying and reproduction so long as the original work is given appropriate credit. Contents may not be used for commercial purposes, or adapted, remixed, transformed or built upon. (https://creativecommons.org/licenses/by-nc-nd/4.0/).

Thieme Medical and Scientific Publishers Private Ltd. A-12, Second Floor, Sector -2, NOIDA -201301, India 


\section{Introduction}

Cancer, a malignant neoplastic lesion, is the second leading cause of deaths globally. ${ }^{1}$ In 2018 alone, 9.6 million lives were lost to cancer-associated deaths worldwide. ${ }^{1}$ Cancer can affect any part of the human body-cervix, mouth, esophagus, larynx, liver, and so forth. ${ }^{2}$ Although not all cases of human cancers have a definitive cure, but many ( 30 to $50 \%$ ) of them are preventable. ${ }^{13}$ The best way to get rid of cancer is to avoid its risk factors. ${ }^{1}$ Avoidance of cancer risk factors is cheaper and safer than cancer cure, by far. ${ }^{13,4}$ The common cancer risk factors are long-term tobacco use, long-term alcohol use, infection with carcinogenic viruses, chronic exposure to ultraviolet radiation, and more. ${ }^{1}$

Due to the heavy public health burden of cancer in the world, the Institute of Medicine (United States) and National Research Council (Unites States) National Cancer Policy Board recommended that health education strategies should be adopted in educating the public about cancer, with the aim of enlightening people about its risk factors, symptoms, and prevention strategies, and as well build positive attitudes toward cancer prevention. ${ }^{1,5}$

With the advent of information and communication technology (ICT), health education activities have been a lot easier unlike before, when such technology was still miniature. ${ }^{6}$ Recent developments in ICT have enabled information pertaining to cancer to be shared to much more people on the globe more than ever before. ${ }^{7}$ One of the recent developments in ICT is the social media. On social media, several pieces of cancer-related information are being shared among people. ${ }^{7}$

Social media is free media; hence there exists a possibility that erroneous information pertaining to cancer can be shared among people. ${ }^{8}$ However, there exists a dearth of literature assessing the influence of cancer-related information as well as the reliability of such information on social media. Hence, there is a need to conduct a study assessing this area of research interest.

\section{Objective}

The aim of this study was to survey the Nigerian public, exploring their opinions on the influence (as per enlightenment) of cancer-related information on social media on them, and explore their opinions on the reliability of cancer-related posts they access on social media platforms.

\section{Materials and Methods}

This study was a descriptive cross-sectional online survey of Nigerians, exploring their opinions on the influence (as per enlightenment) of cancer-related information on social media on them and their opinions on the reliability of cancer-related posts they see on social media platforms.

The study tool was a piloted e-questionnaire (Google Form) developed from relevant scientific literatures and reviewed by public health research experts. ${ }^{8-13}$ The e-questionnaire had four sections. The first section was the informed consent form section. This section informed the participants about the investigators' identity and the aims and objectives of the study, and that their participation is strictly confidential and voluntary. Also, this section obtained consent from all participants. Only those who gave their consent to participate in the study were enabled to respond to the questions/statements in the remaining three sections. The second section obtained information of the demographic characteristics of the participants (such as age, gender, level of education, marital status, occupation, religion, and so forth). The third section obtained information about the history of use of social media among the respondents while the fourth section obtained information about the participants' history of cancer-related educative information acquired on social media platforms and opinions on the reliability of cancer-related information accessed on social media.

The hyperlink to the e-questionnaire was circulated on several discussion forums on online social media platforms (such as WhatsApp, Telegram, Facebook, etc.) and via e-mails. Questionnaire circulation was conducted for a period of 40 days, from January 12, 2020, to February 21, 2020.

The minimum sample size for this study $(n=59)$ was calculated using the Leslie formula for study population $<10,000 .{ }^{14}$ The Leslie formula is as follows:

$$
n=\frac{\left(Z_{\propto / 2}\right)^{2} p q}{e^{2}}
$$

In this formula, $n$ depicts the sample size and $Z_{\propto / 2}$ (equal to 1.96 ) is the value of $Z$ score obtained from the confidence level; $p$ stands for prevalence rate of social media use. The value of $p$ is $96 \%$ and it was derived from a previous study among social work students, ${ }^{15}$ while $q$ is the compliment of $p$ (i.e., $1-p$ ); $e$ is the margin of error, usually estimated at 0.05 .

$$
\begin{gathered}
n=\frac{(1.96)^{2}(1 \times 0.04)}{(0.05)^{2}} \\
n=59
\end{gathered}
$$

A total of 236 Nigerians participated in the online survey. The collected data were analyzed using SPSS version 20 software. The frequency distributions of all variables were determined; the mean and standard deviation (SD) of the respondents' age were also determined. Furthermore, test of associations between relevant variables was done using chi-square test with a $p$-value of $<0.05$ used to determine the level of statistical significance.

Approval to conduct this study was obtained from the Research Committee, Department of Community Health, Aminu Musa Habib College of Health Science and Technology. Electronic informed consent was obtained from all participants. Participation was completely voluntary and anonymous.

\section{Results}

The majority (56.4\%) of the respondents were females, $66.5 \%$ were within the age range of 20 to 29 years, $92.4 \%$ had tertiary level of education, $72.5 \%$ were single, $87.7 \%$ were 
Christians, $94.5 \%$ were residing in Nigeria, and $37.3 \%$ were health care workers (- Table 1).

Virtually all (98.7\%) the respondents had an Internet-enabled phone, $88.1 \%$ identified that they access the Internet always, and $99.6 \%$ were users of social media. Among those respondents that were users of social media $(n=235), 48.2 \%$ identified that they are steadily logged in to social media platforms while $54.9 \%$ of them had been using social media for 6 to 10 years ( - Table 2 ).

The most used social media platforms among those respondents who identified themselves as users of social media $(n=235)$ were WhatsApp $(99.6 \%, 234 / 235)$, Facebook (91.9\%, 216/235), and Instagram (67.2\%, 158/235), while the most educative social media platforms, according to them, were Facebook (37.8\%, 89/235), WhatsApp (22.6\%, 53/235), and Twitter (21.3\%, 50/235) (-Fig. 1).

Table 1 Sociodemographic characteristics of the respondents

\begin{tabular}{|c|c|c|}
\hline Variable $(n=236)$ & Frequency & Percentage \\
\hline \multicolumn{3}{|l|}{ Gender } \\
\hline Male & 103 & 43.6 \\
\hline Female & 133 & 56.4 \\
\hline \multicolumn{3}{|l|}{ Age (y) } \\
\hline$<20$ & 3 & 1.3 \\
\hline $20-29$ & 157 & 66.5 \\
\hline $30-39$ & 67 & 28.4 \\
\hline $40-49$ & 9 & 3.8 \\
\hline \multicolumn{3}{|c|}{ Highest level of education } \\
\hline Primary & 1 & 0.4 \\
\hline Secondary & 8 & 3.4 \\
\hline Tertiary & 218 & 92.4 \\
\hline Others & 9 & 3.8 \\
\hline \multicolumn{3}{|l|}{ Marital status } \\
\hline Single & 171 & 72.5 \\
\hline Married & 64 & 27.1 \\
\hline Separated & 1 & 0.4 \\
\hline \multicolumn{3}{|l|}{ Religion } \\
\hline Christianity & 207 & 87.7 \\
\hline Islam & 29 & 12.3 \\
\hline \multicolumn{3}{|l|}{ Country of residence } \\
\hline Nigeria & 223 & 94.5 \\
\hline United Kingdom & 4 & 1.7 \\
\hline United States & 4 & 1.7 \\
\hline Others & 5 & 2.1 \\
\hline \multicolumn{3}{|l|}{ Occupation } \\
\hline $\begin{array}{l}\text { Health care } \\
\text { worker }\end{array}$ & 88 & 37.3 \\
\hline $\begin{array}{l}\text { Non-health care } \\
\text { worker }\end{array}$ & 148 & 62.7 \\
\hline
\end{tabular}

Table 2 Internet/social media access and usage among respondents

\begin{tabular}{|c|c|c|}
\hline Questions & Frequency & Percentage \\
\hline \multicolumn{3}{|c|}{ Do you use Internet-enabled phone? $(n=236)$} \\
\hline Yes & 223 & 98.7 \\
\hline No & 3 & 1.3 \\
\hline \multicolumn{3}{|c|}{ How often do you access the Internet? $(n=236)$} \\
\hline Always & 208 & 88.1 \\
\hline Sometimes & 23 & 9.7 \\
\hline Seldom & 4 & 1.7 \\
\hline No response & 1 & 0.4 \\
\hline \multicolumn{3}{|c|}{ Do you use social media? $(n=236)$} \\
\hline Yes & 235 & 99.6 \\
\hline No & 1 & 1.4 \\
\hline \multicolumn{3}{|c|}{ Frequency of login to social media platforms $(n=235)$} \\
\hline Steady & 110 & 48.2 \\
\hline Daily & 110 & 48.2 \\
\hline Every other day & 6 & 2.6 \\
\hline Quarterly & 2 & 0.9 \\
\hline \multicolumn{3}{|c|}{ Years of social media usage $(n=235)$} \\
\hline $1-5 y$ & 22 & 9.4 \\
\hline $6-10 y$ & 129 & 54.9 \\
\hline $11-15 y$ & 81 & 34.5 \\
\hline$>15$ y & 3 & 1.3 \\
\hline
\end{tabular}

Also, 96.6\% (227/235) of those respondents who were social media users were of the opinion that social media is very useful for cancer education. However, only $68.5 \%$ (161/235) of those respondents on social media had learnt something about cancer on social media platforms, of which 26.7\% (43/161) and 23.0\% (37/161) got more enlightenment on cancer prevention and rated the cancer information they have accessed on social media to be somewhat reliable, respectively ( - Table 3 ). However, our bivariate analysis showed that no statistically significant relationship exists between the areas where social media has enlightened the respondents on cancer (such as on cancer prevention, cancer treatment, cancer research, cancer awareness, and cancer support) and their gender, age, level of education, religion, country of residence, and occupation $(p>0.05)(-$ Table 4$)$.

\section{Discussion}

The social media is a very large educative platform with 3.5 billion users; this population forms $45 \%$ of the world's population. ${ }^{9,16}$ Social media is a very powerful tool influencing behavioral change among individuals, especially when it comes to health behaviors. ${ }^{9}$ On social media, there are lot of health-related information that flies around, of which some are helpful while some are quite misleading, ${ }^{8}$ and scientific evidence had shown that social media influence can either make or mar healthy behaviors. ${ }^{9-13}$

In this study, we conducted an online survey of the Nigerian public with the primary rationale of exploring their opinions 


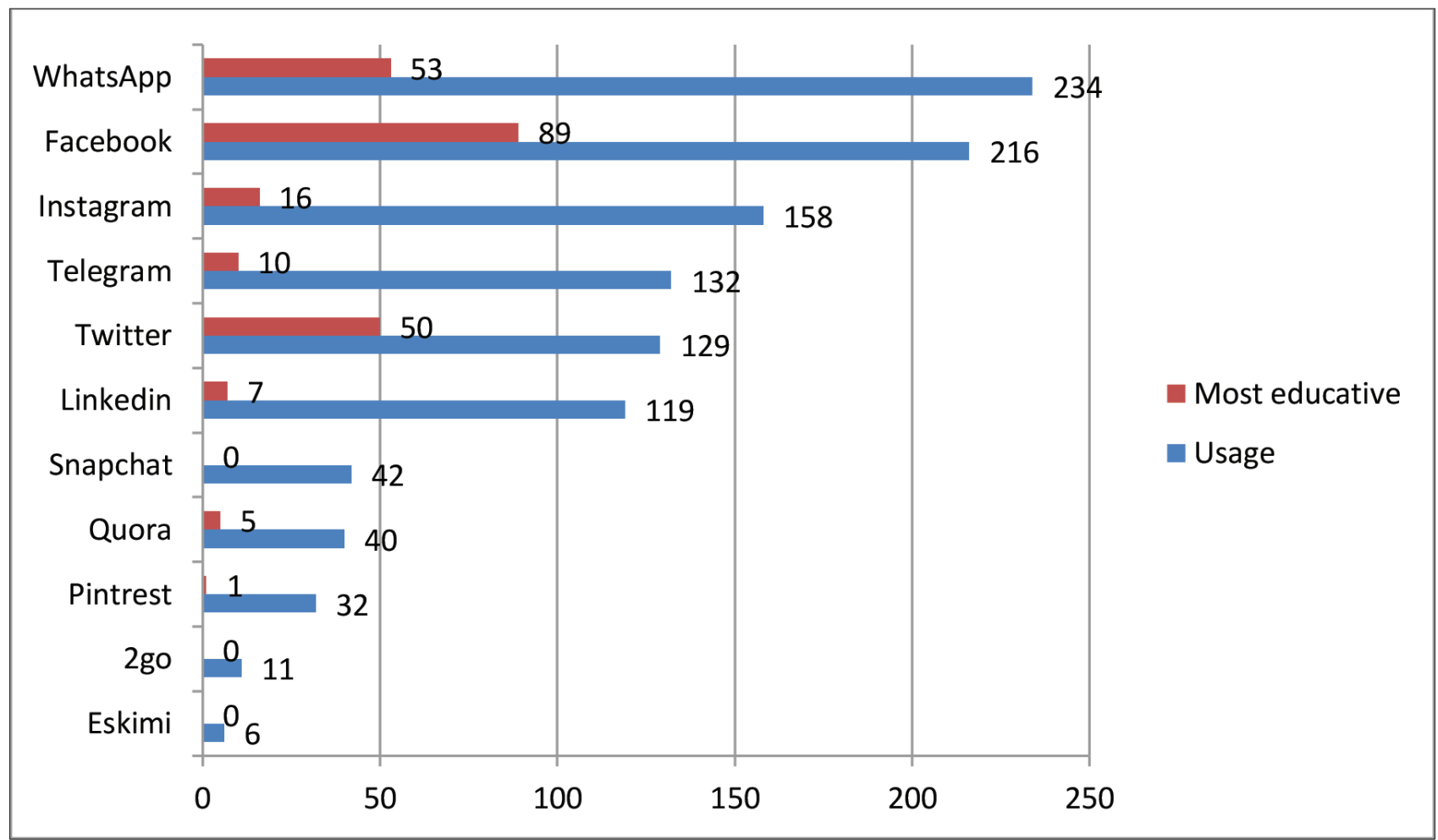

Fig. 1 Social media use and the perceived most educative social media platforms among the respondents who were social media users.

Table 3 Perceived usefulness of social media as a cancer education tool among those respondents that were social media users

\begin{tabular}{|c|c|c|}
\hline Questions & Frequency & $\begin{array}{l}\text { Percentage } \\
\text { (\%) }\end{array}$ \\
\hline \multicolumn{3}{|c|}{$\begin{array}{l}\text { Do you think social media is very useful for cancer education? } \\
(n=235)\end{array}$} \\
\hline Yes & 227 & 96.6 \\
\hline No & 8 & 3.4 \\
\hline \multicolumn{3}{|c|}{$\begin{array}{l}\text { Have you learnt anything about cancer by using social media? } \\
(n=235)\end{array}$} \\
\hline Yes & 161 & 68.5 \\
\hline No & 36 & 15.3 \\
\hline Maybe & 38 & 16.2 \\
\hline \multicolumn{3}{|c|}{$\begin{array}{l}\text { In what area has social media enlightened you more about } \\
\text { cancer? (multiple responses allowed) }(n=161)\end{array}$} \\
\hline Cancer awareness & 157 & 97.5 \\
\hline Cancer prevention & 43 & 26.7 \\
\hline Cancer treatment & 4 & 2.5 \\
\hline Cancer support groups & 5 & 3.1 \\
\hline Cancer research & 15 & 9.3 \\
\hline \multicolumn{3}{|c|}{$\begin{array}{l}\text { How will you generally rate cancer information on social } \\
\text { media? (multiple responses allowed) }(n=161)\end{array}$} \\
\hline Very reliable & 8 & 5.0 \\
\hline Reliable & 117 & 72.7 \\
\hline Indifferent & 66 & 41.0 \\
\hline Somewhat reliable & 37 & 23.0 \\
\hline Very unreliable & 3 & 1.9 \\
\hline
\end{tabular}

on the influence (as per enlightenment) of cancer-related information on social media on them and exploring their opinions on the reliability of cancer-related posts they access on social media platforms. The data generated from this study provided information that is interesting, noteworthy, and of benefit to the body of scientific knowledge.

Many of the respondents in this study were frequent and long-term users of social media; also, WhatsApp, Facebook, and Instagram were the most commonly used social media platforms among them. This finding on the utility rate of social media platform types is closely similar to the global trend of use of social media. ${ }^{17}$ However, by comparing our finding with another related study on social media usage, it was observed that the Twitter, Snapchat, and WhatsApp were the most commonly used social media platforms among Saudi Arabians. ${ }^{13}$ This observed difference in the utility rate of social media platform types between our study respondents and those surveyed Saudi Arabians suggests that geographical variations exists in the rate and preference of use of each social media platform.

Furthermore, Facebook, Twitter, and WhatsApp were the most educative social media platforms reported in this study. In fact, the majority of our respondents had been influenced by what they had seen on these platforms, especially when it comes to their views on health-related matters, decision-making, and habit practice. Hence, this finding strengthens other scientific literatures that had noted that social media is highly influential on human behaviors. ${ }^{9,12}$

It is also noteworthy that the majority of our study respondents rated social media to be a very useful platform for educating the public on issues pertaining to cancer. In fact, 
Table 4 Associations between sociodemographic features of the respondents and areas where they were enlightened more about cancer via social media

\begin{tabular}{|c|c|c|c|c|c|c|}
\hline \multirow[t]{2}{*}{ Variable } & \multicolumn{5}{|c|}{ In what area has social media enlightened you more about cancer? } & \multirow[t]{2}{*}{$p$-Value (df) } \\
\hline & CA & $\mathrm{CP}$ & CT & CSG & CR & \\
\hline \multicolumn{7}{|l|}{ Gender } \\
\hline Male & $56(69.1)$ & $13(16.0)$ & $2(2.5)$ & $1(1.2)$ & $9(11.1)$ & \multirow[t]{2}{*}{$0.532(4)$} \\
\hline Female & $52(66.7)$ & $18(23.1)$ & $2(2.6)$ & $2(2.6)$ & $4(5.1)$ & \\
\hline \multicolumn{7}{|l|}{ Age (y) } \\
\hline$<20$ & $2(66.7)$ & $1(33.3)$ & $0(0.0)$ & $0(0.0)$ & $0(0.0)$ & \multirow[t]{4}{*}{$0.149(12)$} \\
\hline $20-29$ & $79(73.8)$ & $17(15.9)$ & $2(1.9)$ & $0(0.0)$ & $9(8.4)$ & \\
\hline $30-39$ & $25(56.8)$ & $10(22.7)$ & $2(4.5)$ & $3(6.8)$ & $4(9.1)$ & \\
\hline $40-49$ & $2(40.0)$ & $3(60.0)$ & $0(0.0)$ & $0(0.0)$ & $0(0.0)$ & \\
\hline \multicolumn{7}{|c|}{ Level of education } \\
\hline Secondary & $3(60.0)$ & $1(20.0)$ & $1(20.0)$ & $0(0.0)$ & $0(0.0)$ & \multirow[t]{3}{*}{$0.329(8)$} \\
\hline Tertiary & $99(67.3)$ & $3(20.4)$ & $3(2.0)$ & $3(2.0)$ & $12(8.2)$ & \\
\hline Others & $6(85.7)$ & $0(0.0)$ & $0(0.0)$ & $0(0.0)$ & $1(14.3)$ & \\
\hline \multicolumn{7}{|l|}{ Marital status } \\
\hline Single & $85(74.6)$ & $16(14.0)$ & $3(2.6)$ & $0(0.0)$ & $10(8.8)$ & \multirow[t]{3}{*}{$0.023(8)$} \\
\hline Married & $22(50.0)$ & $15(34.1)$ & $1(2.3)$ & $3(6.8)$ & $3(6.8)$ & \\
\hline Separated & $1(100.0)$ & $0(0.0)$ & $0(0.0)$ & $0(0.0)$ & $0(0.0)$ & \\
\hline \multicolumn{7}{|l|}{ Religion } \\
\hline Christianity & $96(68.1)$ & $29(20.6)$ & $4(2.8)$ & $2(1.4)$ & $10(7.1)$ & \multirow[t]{2}{*}{$0.344(4)$} \\
\hline Islam & $12(66.7)$ & $2(11.1)$ & $0(0.0)$ & $1(5.6)$ & $3(16.7)$ & \\
\hline \multicolumn{7}{|c|}{ Country of residence } \\
\hline Nigeria & $104(59.3))$ & 28 (18.7) & $4(2.7)$ & $3(2.0)$ & $11(7.3)$ & \multirow[t]{2}{*}{$0.351(4)$} \\
\hline $\begin{array}{l}\text { Outside } \\
\text { Nigeria }\end{array}$ & $4(44.4)$ & $3(33.3)$ & $0(0.0)$ & $0(0.0)$ & $2(22.2)$ & \\
\hline \multicolumn{7}{|l|}{ Occupation } \\
\hline $\begin{array}{l}\text { Health care } \\
\text { worker }\end{array}$ & 44 (57.9) & $20(26.3)$ & $2(2.6)$ & $2(2.6)$ & $8(10.5)$ & \multirow[t]{2}{*}{$0.133(4)$} \\
\hline $\begin{array}{l}\text { Non-health } \\
\text { care worker }\end{array}$ & $64(77.1)$ & $11(13.30$ & $2(2.4)$ & $1(1.2)$ & $5(6.0)$ & \\
\hline
\end{tabular}

Abbreviations: CA, cancer awareness; CP, cancer prevention; CR, cancer research; CSP, cancer support group; CT, cancer treatment.

many of them had at one time or the other learnt something about cancer via social media platforms, especially in the area of cancer awareness, cancer prevention, cancer treatment, cancer support, and cancer research. Furthermore, cancer-related posts on social media platforms had really influenced the respondents, irrespective of their gender, age, occupation, religion, country of residence, and level of education. Overall, these findings show that social media platforms can be judiciously used in reaching to many people on health information pertaining to cancer.

However, some of our respondents gave judgments that not all cancer-related posts on social media platforms are reliable; this shows that consumers of cancer-related information posted on social media should be consumed cautiously. The circulation of misleading and risky information on cancer is a global phenomenon and this is not surprising. ${ }^{8}$ To ensure that cancer-related information posted on social media is safely consumed, social media users should always verify the reliability and validity of sources of such posts before its final consumption.

Additionally, the need for censoring health-related posts, and not only cancer-related posts, on social media cannot be overemphasized. For example, many of the tobacco-related information (tobacco is a major cancer risk factor) shared on social media platforms are sometimes misleading. ${ }^{8}$ If dangerous and misleading health-related information are not censored on social media, many people's health behaviors will be influenced negatively as a result of the consumption of such information. In a nutshell, health misinformation on social media platforms is a huge threat to public health that requires urgent public health attention. 
However, this study has its limitations. This study was an online survey; hence, it will be difficult to make unguided generalizations based on the survey data, as a limited sample of Nigerians was investigated. Also, the hyperlink to the survey e-questionnaire was not universally circulated via e-mails and social media platforms; therefore, only those Nigerians who had access to the hyperlink to the e-questionnaire had the opportunity to participate in the study.

Notwithstanding these limitations, this study is believed to be the first published study to explore the opinions of Nigerians on the role of the influence and reliability of cancer-related posts on social media platforms.

\section{Conclusion}

In conclusion, this study shows that social media is highly influential in educating Nigerians on issues pertaining to cancer. However, not all cancer-related information posted on various social media platforms is reliable; hence, social media users should always take extra caution while consuming cancer-related posts on social media platforms.

\section{Conflict of Interest}

None declared.

\section{Acknowledgments}

The authors sincerely appreciate all those who participated in the survey.

\section{References}

1 World Health Organization. Cancer. https://www.who.int/newsroom/fact-sheets/detail/cancer. Accessed February 22, 2021

2 Torre LA, Bray F, Siegel RL. Ferlay J, Lortet-Tieulent J, Jemal A. Global cancer statistics, 2012. CA Cancer J Clin 2015; 65(2):87-108

3 World Health Organization. Cancer prevention. https://www. who.int/cancer/prevention/en/. Accessed February 22, 2021

4 Stewart BW, Wild CP,eds., World Cancer Report 2014. Lyon, France: International Agency for Research on Cancer Press; 2014Accessed February 22, 2021

5 Institute of Medicine (US) and National Research Council (US) National Cancer Policy Board. Findings, policy implications, and recommendations. In: Curry SJ, Byers T, Hewitt M, eds. Fulfilling the Potential of Cancer Prevention and Early Detection. Washington, DC: National Academies Press (US); 2003. https://www.ncbi.nlm.nih.gov/books/NBK223931/. Accessed February 22, 2021

6 Lintonen TP, Konu AI, Seedhouse D. Information technology in health promotion. Health Educ Res 2008;23(3):560-566

7 DiCarlo JM, Gopakumar S, Dhillon PK, Krishnan S. Adoption of information and communication technologies for early detection of breast and cervical cancers in low- and middle-income countries. J Glob Oncol 2016;2(4):222-234

8 Kanmodi KK, Adegbile OE, Ogidan IO, Kanmodi PA. What are we learning on social media about shisha? A case study of top 50 short English YouTube shisha videos. Yen Med J 2020;2(4):38-47

9 Prochaska JJ, Coughlin SS, Lyons EJ. Social media and mobile technology for cancer prevention and treatment. Am Soc Clin Oncol Educ Book 2017;37:128-137

10 Cao B, Liu C, Durvasula M, et al. Social media engagement and HIV testing among men who have sex with men in China: a nationwide cross-sectional survey. J Med Internet Res 2017; 19(7):e251

11 Cho H, Li W, Shen L, Cannon J. Mechanisms of social media effects on attitudes toward e-cigarette use: motivations, mediators, and moderators in a national survey of adolescents. J Med Internet Res 2019;21(6):e14303

12 Iftikhar R, Abaalkhail B. Health-seeking influence reflected by online health-related messages received on social media: cross-sectional survey. J Med Internet Res 2017;19(11):e382

13 Bahkali S, Alfurih S, Aldremly M, Alzayyat M, Alsurimi K, Househ M. The prevalence of internet and social media based medication information seeking behavior in Saudi Arabia. Stud Health Technol Inform 2016;226:275-278

14 Leslie K. Survey Sampling. New York: John Wiley and Sons; 1965

15 Ricciardelli LA, Nackerud L, Quinn AE, Sewell M, Casiano B. Social media use, attitudes, and knowledge among social work students: ethical implications for the social work profession. Soc Sci Human Open 2020;2:100008

16 Moshin M. 10 social media statistics you need to know in 2020. https://www.oberlo.com/blog/social-media-marketingstatistics. Published August 6, 2020. Accessed October 12, 2020

17 Statista. Most popular social networks worldwide as of January 2020 , ranked by number of active users. https://www.statista. com/statistics/272014/global-social-networks-ranked-bynumber-of-users/. Accessed October 12, 2020 